\title{
Secondary Bacterial Organizing Pneumonia in a Patient Recovered from COVID-19 Disease: A Case Report
}

\author{
Alaa Al Zaki, Reem Al Argan, Abir Al Said, Fears Al Kuwaiti \\ Department of Internal Medicine, College of Medicine, Imam Abdulrahman Bin Faisal University, King Fahd Hospital of the \\ University, Dammam, KSA \\ Email: aazaki@iau.edu.sa
}

How to cite this paper: Al Zaki, A., Al Argan, R., Al Said, A. and Al Kuwaiti, F. (2021) Secondary Bacterial Organizing Pneumonia in a Patient Recovered from COVID-19 Disease: A Case Report. Case Reports in Clinical Medicine, 10, 46-51. https://doi.org/10.4236/crcm.2021.102007

Received: January 20, 2021

Accepted: February 22, 2021

Published: February 25, 2021

Copyright (C) 2021 by author(s) and Scientific Research Publishing Inc. This work is licensed under the Creative Commons Attribution International License (CC BY 4.0).

http://creativecommons.org/licenses/by/4.0/

\begin{abstract}
COVID-19 disease is a global pandemic caused by Severe Acute Respiratory Syndrome Coronavirus 2 (SARS-CoV2) that mainly presents with pneumonia, but has variable multi-systemic manifestations. Concomitant bacterial infections associated with the acute stage of COVID-19 disease have been rarely reported in the literature. However, to our knowledge, post viral organizing pneumonia (OP) secondary to bacterial infection after recovery from SARS-CoV2 infection has not been noted before. We report a 27-year-old male patient with Type 1 Diabetes Mellitus who presented with fever post recovery from COVID-19 disease for seven weeks and was found to have OP secondary to Klebsiella pneumoniae. Furthermore, the bronchoalveolar lavage was positive for SARS-CoV2 by RT-PCR despite multiple negative nasopharyngeal RT-PCR. The patient was successfully treated with antibiotics only. Therefore, we conclude that early recognition of OP secondary to bacterial infection in patients with COVID-19 disease and prompt antibiotic treatment could avoid the use of a prolonged course of steroids.
\end{abstract}

\section{Keywords}

COVID-19 Disease, Organizing Pneumonia, Secondary Bacterial Infection, Bronchoalveolar Lavage, Severe Acute Respiratory Syndrome Coronavirus 2 (SARS-CoV2)

\section{Introduction}

COVID-19 disease was announced as a pandemic by the World Health Organization (WHO) on March $11^{\text {th }}, 2020$. It is caused by a novel virus named Severe Acute Respiratory Syndrome Coronavirus 2 (SARS-CoV2) [1]. The clinical 
presentation of COVID-19 disease is variable with multisystem involvement, particularly affecting the respiratory system.

Secondary bacterial infections post viral illness have been reported with many viruses including Influenza Virus, Respiratory Syncytial Virus, Parainfluenza Virus and Human Metapneumovirus [2]. The most common post viral bacterial infections are caused by Staphylococcus aureus, Streptococcus pneumoniae and Haemophilus influenzae [2]. This is also true for SARS-CoV2 infection with $0 \%$ - $15 \%$ of patients found to have concomitant bacterial infection [3]. Moreover, there are several reports of organizing pneumonia (OP) associated with these viruses and other coronaviruses such as SARS-CoV and MERS-CoV [4] [5].

$\mathrm{OP}$ is characterized by intra-alveolar granulation tissue, consisting of intermixed myofibroblasts and connective tissue which could be cryptogenic or secondary to infections, drugs, malignancies, etc. OP tends to respond to corticosteroids as first line treatment for this condition [6].

\section{Case Presentation}

This is a 27-year-old male with Type 1 Diabetes Mellitus complicated by diabetic nephropathy with chronic kidney disease stage 4, secondary hyperparathyroidism, and hypertension. He is also trait for sickle cell anemia and alpha thalassemia. He works as a nurse and was required to do nasopharyngeal swab (NPS) RT-PCR for SARS-CoV2 before joining his clinical duty after returning from local lockdown. The result came back to be positive, however, he remained asymptomatic and did not require any treatment. The SARS-CoV2 NPS RT-PCR was repeated four weeks later and was negative. Seven weeks after the first test, he developed fever $\left(38.5^{\circ} \mathrm{C}\right)$ with no other symptoms, SARS-CoV2 NPS RT-PCR was repeated and was negative again. Subsequently, he was admitted to the hospital for investigation due to ongoing fever up to $39^{\circ} \mathrm{C}$ for 4 days. He denied having any respiratory or gastrointestinal symptoms. Systemic review was unremarkable. On examination, the patient looked well. Vital signs were within normal apart from fever at $39^{\circ} \mathrm{C}$. Throat examination showed mild congestion. The rest of systemic examination was unremarkable.

Laboratory investigations showed WBC $3.3 \mathrm{k} / \mathrm{ul}(4-11 \mathrm{k} / \mathrm{ul})$ (Neutrophils count 1.9, lymphocyte count 1.1) Hgb $9.2 \mathrm{~g} / \mathrm{dl}$ (12 - $16 \mathrm{~g} / \mathrm{dl}), \mathrm{MCV} 60.2 \mathrm{ft}$ (80 $94 \mathrm{ft})$, Platelet $116 \mathrm{k} / \mathrm{ul}(150-400 \mathrm{k} / \mathrm{ul})$, BUN $67 \mathrm{mg} / \mathrm{dl}(8.4-21 \mathrm{mg} / \mathrm{dl})$, Creatinine $5.71 \mathrm{mg} / \mathrm{dl}(0.6-1.3 \mathrm{mg} / \mathrm{dl})$, ESR $14 \mathrm{~mm} / \mathrm{h}(0-20 \mathrm{~mm} / \mathrm{hr})$, CRP $1.22(0.1$ $0.5)$, Procalcitonin: $0.14(<0.1)$, electrolytes and liver enzymes were normal. Chest X-ray did not show any infiltration. NPS SARS-CoV2 RT-PCR was negative for the third time.

The patient was admitted for investigation of the ongoing fever. In addition, He had acute kidney injury on top of chronic kidney disease. He was started on Augmentin $600 \mathrm{mg}$ IV q12 due to the clinical finding of pharyngitis. Septic work up including urine culture, blood cultures and virology screening including $\mathrm{EBV}, \mathrm{CMV}$ and HIV were all negative. 
The patient continued to have persistent fever up to $39^{\circ} \mathrm{C}$. Abdominal ultrasound was done to look for infectious focus and was negative. On the $4^{\text {th }}$ day of hospitalization, antibiotic was upgraded empirically to Meropenem to cover for possible superimposed chest infection post COVID-19. This also prompted further investigations with high resolution computed tomography of the chest (HRCT) which showed a focal area of ground glass opacity with surrounding denser ring of consolidation (reverse halo sign) seen at the superior segment of the left lower lobe. Moreover, there were additional areas of patchy consolidation and ground glass opacities in a peripheral and subpleural distribution within the left lower lobe consistent with organizing pneumonia (OP) (Figure 1(A)). The fever resolved after 48 hours of Meropenem initiation. Bronchoscopy was done and showed mild mucosal erythema at the lingular bronchus. Bronchoalveolar lavage (BAL) morphological examination showed few macrophages and gram-positive cocci. BAL culture grew Klebsiella pneumoniae and was negative for Pneumocystis jiroveci, acid fast bacilli and malignant cells. Interestingly, BAL SARS-CoV2 RT-PCR was positive despite multiple negative NPS. The patient completed 7 days of Meropenem and was discharged in good condition. $\mathrm{He}$ did not develop any respiratory symptoms throughout his admission, as such he was not given corticosteroid for OP. Follow up CT scan was repeated after 8 weeks and showed complete resolution of previously seen radiological findings of OP (Figure 1(B)).

\section{Discussion}

Although concomitant secondary bacterial infections associated with COVID-19 disease have been reported in some studies, to our knowledge, this is the first case of OP secondary to bacterial infection (Klebsiella pneumoniae) presenting as a late complication of COVID-19 disease. Furthermore, the BAL was positive for SARS-CoV2 by RT-PCR almost 8 weeks post recovery from COVID-19 disease despite several negative NPS RT-PCR.

It is not uncommon for viral respiratory infections to be associated with secondary bacterial pneumonia either with concomitant viral/bacterial pneumonia

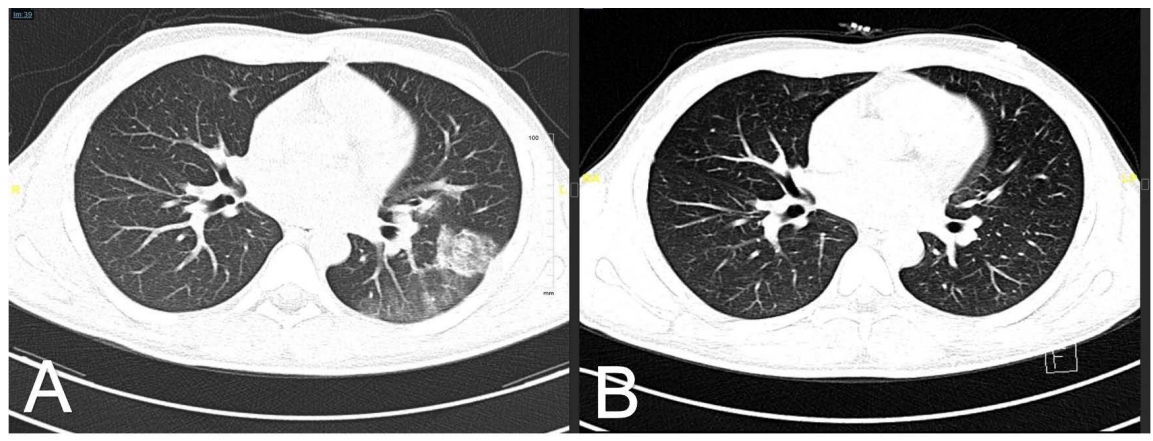

Figure 1. (A) HRCT showing focal area of ground glass opacity with surrounding denser ring of consolidation (reverse halo sign) seen at the superior segment of the left lower lobe; (B) CT scan showing complete resolution of previous radiological findings. 
or develop later during the recovery phase [7]. Data regarding the incidence of secondary bacterial infections with SARS-CoV2 are variable ranging between $0 \%$ - $15 \%$ and were all reported during the acute phase [3]. A retrospective study of 221 patients with SARS-CoV2 infection from Wuhan found bacterial co-infection in $7.7 \%$ which was significantly associated with more severe clinical course and death in ICU [8]. Another recent UK retrospective study of 836 patients with SARS-CoV2 infection showed that $3.2 \%$ had early bacterial co-infection (0 - 5 days), increasing to $6.1 \%$ later during admission [9]. Those infections included bacteremia, community acquired and ventilator associated pneumonia. Staphylococcus aureus was the most common pathogen in community-acquired co-infection, with Pseudomonas and yeast in late-onset infection [9]. Organizing pneumonia (OP) could be cryptogenic or secondary to many etiologies including bacterial and viral infections. Coronaviruses have been reported as a cause of OP during previous pandemics. For example, in a postmortem autopsy study of 20 patients with SARS-CoV infection during 2003 pandemic, a pattern of OP was found in 6 of 20 patients [10]. In addition, OP was reported in a patient with MERS-CoV infection after 14 days of recovery which was treated with steroid [4]. We are reporting the first case of OP secondary to bacterial infection (Klebsiella pneumoniae) 8 weeks after recovery from SARS-COV2 infection that was successfully treated with antibiotic without requiring steroid therapy. Although corticosteroids are commonly used to treat OP, some patients with minimal symptoms were successfully treated with antibiotics such as macrolides or had a spontaneous recovery [11].

In this patient, BAL RT-PCR was positive for SARS-CoV2 almost 8 weeks after recovery despite several negative NPS RT-PCR. SARS-CoV2 viral shedding duration is variable and could be detected months after illness, however, it does not necessarily indicate ongoing infectivity [5] [12]. In a case series of 56 patients with COVID-19 disease, the longest duration of positive SARS-CoV2 RT-PCR was 42 days with a median duration of 24 days [13].

A recent systematic review reported SARS-CoV2 RNA shedding for longer than 14 days with a maximum duration of 35 days. Yet, Infectivity determined by the duration of live viral culture detection declines after day 8 even among cases with ongoing high viral loads [14].

The duration of positive BAL RT-PCR has not been previously reported, in our patient it was 56 days. Several factors were linked to prolonged viral shedding of SARS-CoV2. In a retrospective study of 113 patients with COVID-19 disease, male sex, delayed hospital admission and mechanical ventilation were associated with prolonged SARS-CoV2 RNA shedding [15].

\section{Conclusion}

Early recognition and prompt antibiotic treatment of OP secondary to bacterial infection may avoid the use of prolonged course of steroid. Clinicians should remain vigilant for secondary bacterial infections associated with SARS-CoV2 infections. 


\section{Declaration of Patient Consent}

The authors certify that all appropriate consent forms have been obtained from the patient to publish this report. In the forms, the patient has given consent for his images and other clinical information to be reported in the Journal. The patient understood that his names and initials will not be published and due efforts will be made to conceal identity, but anonymity cannot be guaranteed.

\section{Conflicts of Interest}

The authors declare no conflicts of interest regarding the publication of this paper.

\section{References}

[1] World Health Organization (2020) WHO Director-General's Opening Remarks at the Media Briefing on COVID-19-11 March 2020.

https://www.who.int/dg/speeches/detail/who-director-general-s-opening-remarks-a t-the-media-briefing-on-covid-19---11-march-2020

[2] Morris, D.E., Cleary, D.W. and Clarke, S.C. (2017) Secondary Bacterial Infections Associated with Influenza Pandemics. Frontiers in Microbiology, 8, 1041.

http://journal.frontiersin.org/article/10.3389/fmicb.2017.01041/full https://doi.org/10.3389/fmicb.2017.01041

[3] Wu, C.-P., Adhi, F. and Highland, K. (2020) Recognition and Management of Respiratory Co-Infection and Secondary Bacterial Pneumonia in Patients with COVID-19. Cleveland Clinic Journal of Medicine, 87, 659-663. https://doi.org/10.3949/ccjm.87a.ccc015

[4] Kim, I., Lee, J.E., Kim, K.H., Lee, S., Lee, K. and Mok, J.H. (2016) Successful Treatment of Suspected Organizing Pneumonia in a Patient with Middle East Respiratory Syndrome Coronavirus Infection: A Case Report. Journal of Thoracic Disease, $\mathbf{8}$, E1190-E1194. https://doi.org/10.21037/jtd.2016.09.26

[5] Zheng, S., Fan, J., Yu, F., Feng, B., Lou, B., Zou, Q., et al. (2020) Viral Load Dynamics and Disease Severity in Patients Infected with SARS-CoV-2 in Zhejiang Province, China, January-March 2020: Retrospective Cohort Study. BMJ, 369, m1443. https://doi.org/10.1136/bmj.m1443

[6] Cordier, J.F. (2006) Cryptogenic Organising Pneumonia. European Respiratory Journal, 28, 422-446. https://doi.org/10.1183/09031936.06.00013505

[7] van der Sluijs, K.F., van der Poll, T., Lutter, R., Juffermans, N.P. and Schultz, M.J. (2010) Bench-to-Bedside Review: Bacterial Pneumonia with Influenza-Pathogenesis and Clinical Implications. Critical Care, 14, Article No. 219. https://doi.org/10.1186/cc8893

[8] Zhang, G., Hu, C., Luo, L., Fang, F., Chen, Y., Li, J., et al. (2020) Clinical Features and Short-Term Outcomes of 221 Patients with COVID-19 in Wuhan, China. Journal of Clinical Virology, 127, Article ID: 104364. https://doi.org/10.1016/j.jcv.2020.104364

[9] Hughes, S., Troise, O., Donaldson, H., Mughal, N. and Moore, L.S.P. (2020) Bacterial and Fungal Coinfection among Hospitalized Patients with COVID-19: A Retrospective Cohort Study in a UK Secondary-Care Setting. Clinical Microbiology and Infection, 26, 1395-1399. https://doi.org/10.1016/j.cmi.2020.06.025

[10] Hwang, D.M., Chamberlain, D.W., Poutanen, S.M., Low, D.E., Asa, S.L. and Butany, 
J. (2005) Pulmonary Pathology of Severe Acute Respiratory Syndrome in Toronto. Modern Pathology, 18, 1-10. https://doi.org/10.1038/modpathol.3800247

[11] Wells, A.U. and Hirani, N. (2008) Interstitial Lung Disease guideline: The British Thoracic Society in collaboration with the Thoracic Society of Australia and New Zealand and the Irish Thoracic Society. Thorax, 63, v1-v58. http://dx.doi.org/10.1136/thx.2008.101691

[12] Carroll, D.M., Strayer, L., Nardone, N., Pacek, L.R., Kozink, R.V., Tessier, K., et al. (2020) Development and Piloting Testing of an Experimental Tobacco and Nicotine Product Marketplace. Nicotine \& Tobacco Research, 22, 1230-1234. https://doi.org/10.1093/ntr/ntz195

[13] Xiao, A.T., Tong, Y.X. and Zhang, S. (2020) Profile of RT-PCR for SARS-COV-2: A Preliminary Study from 56 COVI-19 Patients. Clinical Infectious Diseases, 71, 2249-2251. https://doi.org/10.1093/cid/ciaa460

[14] Jefferson, T., Spencer, E., Brassey, J. and Heneghan, C. (2020) Viral Cultures for COVID-19 Infectivity Assessment: A Systematic Review. Clinical Infectious Diseas es, ciaa1764. https://doi.org/10.1093/cid/ciaa1764

[15] Xu, K., Chen, Y., Yuan, J., Yi, P., Ding, C., Wu, W., et al. (2020) Factors Associated with Prolonged Viral RNA Shedding in Patients with Coronavirus Disease 2019 (COVID-19). Clinical Infectious Diseases, 71, 799-806.

https://doi.org/10.1093/cid/ciaa351 